\title{
Produtivismo acadêmico: representação da universidade como espaço de reprodução social
}

\author{
Academic productivism: representation \\ of the university as a space for social reproduction
}

\author{
Josimar de Aparecido Vieira ${ }^{1}$ \\ Ana Sara Castaman ${ }^{2}$ \\ Mario Luiz Junges Júnior ${ }^{3}$
}

Resumo: Partindo do pressuposto de que as relações produtivistas encontram respaldo no padrão de produção da sociedade capitalista, este artigo vem com o intuito de contribuir para o entendimento da educação universitária como espaço de reprodução das formações sociais dominantes. Para tanto, foi produzido por meio da pesquisa bibliográfica concentrada em obras de autores como Althusser (1970), Bourdieu e Passeron (1992), Bianchetti e Machado (2009), Sguissardi e Silva Júnior (2009), Sguissardi (2010), Durkheim (2011), Saviani (2012), Bianchetti e Valle (2014), Patrus, Dantas e Shigaki (2015) e Guill, Zanferrari e Almeida (2017), entre outros. Tal modo de abordagem se assenta como pesquisa exploratória e descritiva e foi desenvolvido seguindo abordagem qualitativa e dialética, seguindo os movimentos e contradições próprios dos espaços educativos. Como organização, o trabalho encontrase estruturado de modo que apresenta as construções teóricas que evidenciam a educação escolar como espaço de reprodução e de manutenção da estrutura social dominante; as relações de produção existentes nas universidades e a questão do produtivismo acadêmico e a universidade como um espaço de reprodução da ideologia dominante. Esses pontos, apresentados de forma interligada e interdependente, indicam que o entendimento da escola como Aparelho Ideológico de Estado fornece subsídios para o reconhecimento da realidade das universidades e seu acercamento com a formulação de produtivismo acadêmico, levando à compreensão da universidade enquanto ambiente de reprodução social.

Palavras-chave: Produtivismo acadêmico. Aparelhos ideológicos. Reprodução social. 
Abstract: Based on the assumption that productivist relations are supported by the production pattern of capitalist society, this article aims to contribute to the understanding of university education as a space for the reproduction of dominant social formations. To this end, it was produced through bibliographical research concentrated on works by authors such as Althusser (1970), Bourdieu and Passeron (1992), Bianchetti and Machado (2009), Sguissardi e Silva Júnior (2009), Sguissardi (2010), Durkheim (2011), Saviani (2012), Bianchetti and Valle (2014), Patrus, Dantas and Shigaki (2015) and Guill, Zanferrari and Almeida (2017), among others. This approach is based on exploratory and descriptive research and was developed following a qualitative and dialectical approach, following the movements and contradictions proper to educational spaces. As an organization, the work is structured so that it presents the theoretical constructions that highlight school education as a space of reproduction and maintenance of the dominant social structure; the relations of production existing in universities and the question of academic productivism and the university as a space of reproduction of the dominant ideology. These points, presented in an interconnected and interdependent way, indicate that the understanding of the school as an Ideological State Device provides subsidies for the recognition of the reality of universities and its approach to the formulation of academic productivism, leading to the understanding of the university as an environment of social reproduction.

Keywords: Academic productivism. Ideological devices. Social reproduction.

Instituto Federal de Educação, Ciência e Tecnologia do Rio Grande do Sul | Programa de Pós-Graduação em Educação Profissional e Tecnológica | Chapecó | SC | Brasil. Contato: josimar.vieira@ sertao.ifrs.edu.br. ORCID: https://orcid.org/0000-0003-3156-8590

${ }^{2}$ Instituto Federal do Rio Grande do Sul | Programa de Pós-Graduação em Educação Profissional e Tecnológica | Passo Fundo | RS | Brasil. Contato: ana.castaman@ @ertao.ifrs.edu.br. ORCID: https://orcid.org/0000-0002-5292$\underline{3646}$

${ }^{3}$ Universidade de Passo Fundo | Programa de Pós-Graduação em Educação | Passo Fundo | RS | Brasil. Contato: mariojunges@ hotmail.com. ORCID: https://orcid.org/0000-0002-1148-2709

- Recebido em: 28 de abril de 2020

- Aprovado em: 15 de junho de 2020

DOI: http://dx.doi.org/10.1590/S1414-40772021000100014

Este é um artigo publicado em acesso aberto sob uma licença Creative Commons https://creativecommons.org/licenses/by-nc/4.0/ 


\section{Introdução}

Nos últimos anos, o espaço acadêmico tem sido foco de estudos teóricos (construção ou testagem de teorias), metodológicos (indagação de instrumentos, elaboração de técnicas e discussão de abordagens teóricas), empíricos (mensuração da realidade social) e práticos (intervenção na realidade) (MINAYO, 2004) relativos à sua organização e aos seus resultados, frente às políticas de avaliação e de financiamento, principalmente da Pós-Graduação Stricto Sensu. Grande parte dos artigos, como os de Bianchetti e Machado (2009), Patrus, Dantas e Shigaki (2015), Guill, Zanferrari e Almeida (2017) abordam sobre o aprofundamento de uma prática denominada de produtivismo acadêmico, modelo que se assemelha ao já conhecido fordismo (WOOD JR., 2016). De acordo com Sguissardi (2010), produtivismo acadêmico é um

Fenômeno em geral derivado dos processos oficiais ou não de regulação e controle, supostamente de avaliação, que se caracteriza pela excessiva valorização da quantidade da produção científico-acadêmica, tendendo a desconsiderar a sua qualidade. [...]. Tem sua origem nos anos 1950, nos EUA. Tornou-se mundialmente conhecido pela expressão public or perish, significando que os professores/pesquisadores universitários que não publicassem de acordo com os parâmetros postos como ideais pelos órgãos financiadores, pela burocracia universitária ou pelo mercado, veriam sua carreira definhar e fenecer (p. 1).

No Brasil, o produtivismo acadêmico começou a ser tratado nos anos 70 e, a partir da década de noventa, por meio do modelo da Coordenação de Aperfeiçoamento de Pessoal de Nível Superior (CAPES) de avaliação, passou a ser discutido com mais intensidade, sendo que a crítica até hoje condena a preocupação com a quantidade e não a busca da qualidade, ou ainda, sobre os benefícios das pesquisas para a sociedade (BIANCHETTI; MACHADO, 2009, SGUISSARDI; SILVA JÚNIOR, 2009).

A avaliação da Capes se dá pela competitividade que se encontra instaurada nos programas de Pós-Graduação Stricto Sensu e na vida profissional dos pesquisadores, professores e estudantes. Para isso, os programas de Pós-Graduação passaram por profundas mudanças na sua forma de financiamento, gestão e avaliação, as quais afetaram pesquisadores e a própria qualidade da produção do conhecimento (BIANCHETTI; VALLE, 2014). Nesta direção, Sguissardi (2010) elucida que, proveniente dos processos de avaliação da PósGraduação, o produtivismo acadêmico é entendido como um episódio reconhecido pela demasiada valorização da quantidade de produção científica desenvolvida no contexto acadêmico e pela precária atenção à sua qualidade, à formação e ao bem-estar dos pesquisadores.

Partindo destas considerações iniciais e do pressuposto de que as relações produtivistas encontram respaldo no padrão de produção da sociedade capitalista, este artigo tem por 
finalidade conhecer os conceitos e fundamentos das teorias crítico-reprodutivistas, de modo a contribuir para o entendimento da educação universitária como espaço de reprodução das formações sociais dominantes. Diante deste propósito, este estudo se caracteriza como pesquisa exploratória e descritiva e foi desenvolvido seguindo abordagem que se assenta predominantemente numa perspectiva qualitativa e dialética, seguindo os movimentos e as contradições próprios dos espaços educativos. Orienta-se naquilo que Minayo (2004) salienta, ou seja, a pesquisa qualitativa trabalha com o universo de significados, motivos, aspirações, crenças, valores e atitudes, o que corresponde a um espaço mais profundo das relações, dos processos e dos fenômenos que não podem ser reduzidos à operacionalização de variáveis.

Contou com pesquisa bibliográfica que fundamenta e direciona o trabalho, realizada a partir de material já publicado, constituído principalmente de livros, artigos de periódicos e, atualmente, com material disponibilizado na Internet com incidência em obras de autores como Althusser (1970), Bourdieu e Passeron (1992), Bianchetti e Machado (2009), Sguissardi e Silva Júnior (2009), Sguissardi (2010), Durkheim (2011), Saviani (2012), Bianchetti e Valle (2014), Patrus, Dantas e Shigaki (2015) e Guill, Zanferrari e Almeida (2017), entre outros que se ocupam com esta temática.

Com esta perspectiva demarcada, o teor deste artigo se adensa no fenômeno produtivismo acadêmico a partir da compreensão dos conceitos e fundamentos das teorias crítico-reprodutivistas e do entendimento da educação universitária como espaço de reprodução das formações sociais dominantes. Com isso, a estruturação deste texto se concentrou em três seções: inicia examinando as construções teóricas que evidenciam a educação escolar como espaço de reprodução e de manutenção da estrutura social dominante; na segunda seção encontram-se pautadas as relações de produção existentes nas universidades, a partir do contato com autores que se propuseram a trabalhar a questão do produtivismo acadêmico e, na sequência, o leitor é encaminhado para o entendimento da universidade, não mais como um espaço autônomo de construção de conhecimento, mas como campo de reprodução da ideologia dominante. Por fim, são discorridas as considerações finais deste estudo.

\section{As teorias crítico-reprodutivistas, a escola e a reprodução social}

Trabalhar em uma perspectiva que descreve a proximidade entre os escritos de Althusser (1970) sobre Aparelhos Ideológicos do Estado (AIE) e a educação em um projeto pedagógico marcado por uma pedagogia da reprodução social, examinada por Saviani (2012), requer um encontro com o pensamento desses autores acerca de seus conceitos. 
Saviani (2012), ao trabalhar com questões referentes a marginalidade e a sua relação com a escolarização, traz à baila dois grupos de teorias educacionais que se apresentam conforme a perspectiva do papel da educação e sua interface com a sociedade. De um lado, temos concepções que percebem a sociedade como um corpo social coeso que, em determinadas situações, depara-se com distorções que são corrigidas pela educação em retomada da harmonia. Conforme salienta Saviani, às chamadas teorias não-críticas são assim classificadas por não reconhecerem as influências da sociedade na educação, ou seja, a educação é vista como autônoma e capaz de corrigir distorções que se apresentam como fenômenos acidentais.

O mesmo Saviani aponta ainda a produção de conceitos que identificam a sociedade, não como um conjunto coeso e harmônico, mas caracterizado pela divisão de classes fortemente marcada pelas relações de produção. Neste modelo, a educação aparece como dependente e legitimadora da sociedade na qual se encontra. Na perspectiva crítico-reprodutivista, o autor descreve o problema da marginalidade como parte da sociedade, resultante da forma como está estruturada. Quanto ao papel da educação, cabe garantir a manutenção da estrutura social, na qual está subordinada. Complementando, Saviani $(2012$, p. 16) chama a atenção para o fato de que, em sua origem, a escola enquadra-se como capaz de equalizar a sociedade, ou seja, “[...] atualmente se torna cada vez mais discriminadora e repressiva. Todas as reformas escolares fracassaram, tornando cada vez mais evidente o papel que a escola representa: reproduzir a sociedade de classes e reforçar o modo de produção capitalista".

Seguindo a mesma linha de pensamento apresentada por Saviani, de uma escola voltada para a reprodução de um ideal, é possível identificar em Durkheim (2011) uma elaboração social de homem que deve ser construído pela educação. Com esse construto, o autor identifica na educação o papel de engendrar sujeitos sociais. "Portanto, para a sociedade, a educação é apenas o modo pelo qual ela prepara no coração das crianças as condições essenciais de sua própria existência" (p. 53).

Por este prisma, as avaliações de Althusser (1970) acerca da escola como AIE dominante ganham força, essencialmente por transitar pela lógica de reprodução. Althusser (1970, p. 62-63) argumenta que “[...] todos os Aparelhos Ideológicos de Estado (AIE), sejam eles quais forem, concorrem para um mesmo resultado: a reprodução das relações de produção, isto é, das relações de exploração capitalistas”. O motivo que leva a escola a assumir o papel dominante, detalha Althusser, está intimamente atrelado às condições de acesso às crianças, à obrigatoriedade e ao tempo que pode dispor de sua presença, independente da classe social que pertençam. 
Nesta mesma perspectiva sugerida por Althusser, sobre as possibilidades encontradas na escola que lhe elevou à posição de AIE dominante, é possível encontrar em Bourdieu e Passeron (1992), a ideia de uma pretensa neutralidade do sistema de ensino que lhe confere ares de autonomia em relação aos grupos ou classes sociais. Com isso, a escola assume uma posição de poder justamente por não parecer possuir tal poder.

Retomando as ideias acerca dos AIE e a compreensão da ligação existente entre esse conceito e a reprodução de um modelo de sociedade, é necessário que se tenha clara a construção proposta por Althusser no que diz respeito aos Aparelhos de Estado. Na tentativa de abrir para o entendimento do leitor acerca do conceito do AIE, Althusser, ao descrever a teoria marxista, propõe que haja a compreensão da existência de um Aparelho de Estado composto por instituições, como Governo, Exército, Polícia, Administração, Prisões, Tribunais e demais espaços que estruturam aquilo que é denominado de Aparelho Repressivo de Estado (ARE). O uso da expressão Repressivo está vinculado ao trabalho executado por essas instâncias que, na sua base, se encontra marcado pelo uso da violência.

Partindo do pressuposto da existência de um ARE, Althusser remete o leitor para a construção da ideia de AIE composto, para além da escola, por diversas instituições que não se confundem com os Repressivos por ter em sua estruturação prática o uso da ideologia, tendo a repressão como mecanismo secundário. Nessa estrutura são descritos os Aparelhos: escolar, religioso, familiar, jurídico, político, sindical, da informação e cultural.

Althusser (1970) chama a atenção para o fato de que o funcionamento ideológico dos AIE tem como fundamento a ideologia da classe dominante. Tendo como base que a classe dominante é quem detém o poder de Estado e, consequentemente, do aparelho Repressivo, e admitindo-se que essa mesma classe se encontra ativa nos AIE, se verifica o trabalho de ambos (Aparelhos Repressivos e ideológicos) para um mesmo fim, a reprodução das relações de produção capitalista com suas características de exploração. Com esse viés, Saviani (2012, p. 23) explica que “[...] o AIE escolar, em lugar de instrumento de equalização social, constitui um mecanismo construído pela burguesia para garantir e perpetuar seus interesses".

Neste ponto é possível adentrarmos nos espaços, propostos por Althusser, que retratam os direcionamentos dados por esses interesses. Como o próprio autor retrata, para que seja possível garantir a continuidade da produção, se faz necessário que as condições de reprodução sejam mantidas, isto é, para que uma formação social se perpetue é imprescindível que sejam criadas conjunturas de manutenção.

Para Althusser, as ferramentas ou engrenagens que mantém em giro a produção de determinada formação social são as forças produtivas e as relações de produção. Para tanto, 
Althusser aproxima sua explicação do dia a dia de uma fábrica, trazendo aspectos palpáveis das necessidades de reprodução, apresentando a infinidade de ligações necessárias para a manutenção das atividades produtivas. Uma delas é garantir que haja equipamentos, logo devem ser reproduzidos os maquinários necessários ou condições materiais.

Além disso, é importante pensar que uma indústria ou formação social não se faz apenas com máquinas ou condições materiais. Para que possa colocar em funcionamento esses equipamentos é imperioso que se consiga reproduzir a força de trabalho (ALTHUSSER, 1970). Esta é uma construção que poderá nos levar ao entendimento das instituições de ensino enquanto condições materiais de reprodução de uma formação social.

\footnotetext{
Dissemos que a força de trabalho disponível devia ser "competente", isto é, apta a ser posta a funcionar no sistema complexo do processo de produção. O desenvolvimento das forças produtivas e o tipo de unidade historicamente constitutivo das forças produtivas num momento dado produzem o seguinte resultado: a força de trabalho deve ser (diversamente) qualificada e portanto reproduzida como tal (ALTHUSSER, 1970, p. 20).
}

Ainda sobre qualificação, Althusser chama a atenção para o fato de que esta possui como norte as demandas sociais, tendo assim, a necessidade de considerar as características de divisão social e técnica do trabalho. Para tanto, especifica Althusser, a sociedade capitalista faz uso das instituições escolares, ponto demarcado também por Durkheim (2011), quando orienta que a educação se organiza conforme as profissões, construindo uma educação para cada direcionamento. "Uma instrução para os operários, outra para os técnicos, uma terceira para os engenheiros, uma outra para os quadros superiores, etc.” (ALTHUSSER, 1970, p. 20-21), de tal forma que seja garantida a manutenção da submissão ao que está estabelecido, reproduzindo não só a força de trabalho, mas um modelo de relação de produção e de trabalho, legitimando a sujeição, a dominação, as desigualdades e aos privilégios, como destaca Saviani (2012).

A partir dessa contextualização sobre as construções teóricas que evidenciam a educação escolar como espaço de reprodução e de manutenção da estrutura social dominante, na próxima seção são analisadas as relações de produção existentes nas universidades, enfatizando, em especial, o produtivismo acadêmico.

\section{Produtivismo acadêmico: reflexos de um ideário neoliberal}

São incontáveis as mudanças ocorridas no mundo do trabalho nas últimas décadas. Vem à tona uma forte corrente voltada para organização gerencial que tem adentrado em espaços anteriormente distantes da lógica empresarial, como as escolas e as universidades, trazendo, por um lado, um otimismo em relação à eficiência dessas instituições e, por outro lado, o 
crescimento da precarização do trabalho (BERNARDO, 2014). Tal modelo gerencial tem sido caracterizado como capitalismo acadêmico, termo proposto por Slaughter e Leslie em 1997, com o livro Academic Capitalism and the New Economy.

Nesta perspectiva, de um capitalismo acadêmico, tornam-se claras as influências de organismos internacionais como o Banco Mundial e a Organização Mundial do Comércio, a partir do incentivo às reformas que objetivem maior produtividade e menor custo para as instituições públicas. Além disso, vem sendo evidenciado um projeto de universidade marcado pela produtividade e pela competição no desenvolvimento de produtos que possam interessar à clientela, que podem ser estudantes ou ainda, instituições de fomento. A universidade, local hegemônico para a pesquisa, passa a trabalhar com critérios até então exclusivos do mundo corporativo (BIANCHETTI; MACHADO, 2009). Para Silva Junior, Gonçalves-Silva e Moreira (2014, p. 1426) a pesquisa se dá

[...] seja por intermédio de programas de pós-graduação stricto sensu, pós-graduação
lato sensu, iniciação científica, trabalhos finais de graduação ou através de sua
estimulação e exercício paralelo à docência, à publicação de dissertações, teses, livros,
artigos em periódicos e trabalhos em anais de eventos científicos se constituem formas
de circulação do conhecimento produzido, tornando-os públicos.

Conforme explicam Bianchetti e Machado (2009), Bernardo (2014) e Shigaki e Patrus (2016), um ponto que pode ser visto como marco da transformação da universidade diz respeito à modificação da CAPES em uma fundação pública, órgão regulamentador e responsável pela avaliação do desempenho dos Programas de Pós-graduação Stricto Sensu (PPGSS). Assim, "[...] adota cinco quesitos com pesos diferentes na composição da nota final: proposta do programa; corpo docente; corpo discente; teses e dissertações; produção intelectual e inserção social" (CASTANHA; GRÁCIO, 2015, p. 132). A partir desses critérios e conforme a nota atribuída ao programa, o mesmo terá direito a bolsas, a possibilidade de acessos em portais da CAPES gratuitamente, a participar de editais de fomento (especiais), entre outros.

Diante do exposto, a CAPES passou a utilizar uma lógica de competição, advinda do modelo norte-americano, vinculada ao financiamento da pós-graduação. Com esse padrão, as avaliações da CAPES fundamentam-se num quantitativo de produtividade intelectual, por meio de números que comprovem o trabalho dos sujeitos da pós-graduação e da pesquisa. Esse critério aumenta a busca dos pesquisadores para publicar investigações científicas em periódicos de excelência, de forma individual e em parceria intra e interinstitucional. As revistas científicas são fontes formais de comunicação da ciência e originaram-se "como uma evolução da comunicação informal, que consistia no uso de cartas, atas ou memórias das reuniões 
científicas para transferência da informação entre pesquisadores" (GONÇALVES; RAMOS; CASTRO, 2006, p. 165). Para Vosgerau, Orlando e Meyer (2017), fica evidente que as universidades direcionam suas ações para a pesquisa por ser dessas que se origina grande parte do seu financiamento.

Com essa orientação avaliativa, a universidade aproxima-se do que é visto no mundo empresarial, colocando o artigo como a mercadoria de produção em massa. "E pode-se acrescentar, adotando um modelo de organização do trabalho que associa o discurso da flexibilidade com a rigidez das metas de produtividade, indicando uma clara inspiração toyotista" (BERNARDO, 2014, p. 130). Embora a adoção de tecnologias de gestão pudesse contribuir para uma diminuição da sobrecarga de trabalho, o caminho inverso vem sendo demarcado nas relações de produção, igualando cada vez mais a universidade daquilo que se identifica nas empresas (BIANCHETTI; MACHADO, 2009).

A aproximação da academia com conceitos do mundo corporativo, destacam Bianchetti e Machado, coloca a universidade na busca pela ampliação das capacidades produtivas de seus trabalhadores, com vistas a melhores qualificações avaliativas e, em consequência disso, montantes maiores de recursos. É nesse contexto que surge o conceito de produtivismo acadêmico "[...] entendido neste artigo como um fenômeno derivado dos processos de regulação e controle, em particular, os de avaliação, que se caracterizam pela excessiva valorização da quantidade de produção científico-acadêmica, tendendo a desconsiderar a sua qualidade" (PATRUS; DANTAS; SHIGAKI, 2015, p. 1). Dias e Serafim (2015, p. 343) ressaltam que o "[...] produtivismo é, de certa forma, a tradução do imperativo da eficiência no âmbito da pesquisa".

No entendimento de Shigaki e Patrus (2016), o termo produtivismo acadêmico aproxima-se da expressão performatividade acadêmica e está ligado a uma prática de produção exacerbada, sem que seja dada a devida importância para a qualidade dessa produção. O uso de performatividade ganha força pela sua ligação com os resultados performáticos obtidos por meio do Currículo Lattes. Essa terminologia aproxima-se da concepção de Bernardo (2014), que evidencia não se publicar pela relevância de divulgação de resultados das investigações, mas pela possibilidade de ampliar o currículo.

Essa corrida por publicações, orientam Shigaki e Patrus (2016), tem ligação com uma lógica industrial de desempenho. Os pesquisadores passam a ser avaliados pelo número de artigos produzidos em determinado período, gerando a formulação da expressão publish or perish, que revela uma necessidade de se atingir metas de publicações ou ter sua carreira prejudicada. Este fator tem levado à dilatação das jornadas de trabalho, como revelam 
Bianchetti e Machado (2009), ou conduzido ao chamado suicídio acadêmico (SILVA, 2009), aqueles que não se socializam com o sistema.

Oliveira (2006) faz considerações acerca desse modelo de produtividade dos pesquisadores:

\begin{abstract}
A faceta da reforma neoliberal, que tende a substituir a dádiva pela mercadoria como princípio organizador da ciência, é o peso atribuído à avaliação quantitativa da produtividade dos pesquisadores, individualmente ou agrupados por departamento ou outra unidade institucional de pesquisa. Essa diretriz revela bem a força das concepções neoliberais, uma vez que consegue se impor afrontando instituições muito sólidas a respeito do valor de obras criativas, não só na ciências mas também nas artes. A idéia [sic] de que um cientista que publica duas vezes mais artigos que outro é duas vezes mais produtivo, sem levar em conta a qualidade das obras, é chocante mesmo para o mais elementar senso comum. Essa contradição não é ignorada e motiva a elaboração de formas mais sofisticadas de avaliação, como a que leva em conta o número de citações que cada publicação recebe na literatura especializada. Mas, ainda nesse caso, a ênfase é não apenas no aspecto quantitativo, mas também no requisito de que as quantidades envolvidas devem ser mensuráveis de forma inteiramente objetiva. É difícil explicar de outra maneira tal diretriz, a não ser como um recurso para encaixar a força o conhecimento científico no molde da mercadoria (p. 252-253).
\end{abstract}

Neste caso, o foco não passa a ser na pesquisa em si ou no avanço do conhecimento a respeito de um determinado assunto, mas na aposta em escrita de temas com maior probabilidade de publicação e em conhecer o periódico com maior fator de impacto e de webqualis para, consequentemente, tentar publicar neste escopo, conforme enfatiza Kunz (2012, p. 9, grifo do autor)

\begin{abstract}
A questão crucial sobre o que se está pesquisando/escrevendo é substituída pela pergunta qual o Qualis da revista em que se publica. Os próprios problemas de pesquisa são ultimamente escolhidos por esta questão, ou seja, para mais pontos na Capes [...]. Assim, o problema do sentido, da função e relevância social das pesquisas científicas, bem como as questões sobre que conhecimento e para que formação não fazem mais parte dessas novas preocupações científicas.
\end{abstract}

Bianchetti e Machado (2009) chamam a atenção para o fato de que a inserção do capitalismo nos espaços acadêmicos, além de uma ampliação da jornada de trabalho para os professores, garantindo maior produtividade pela organização desvinculada de um tempo e espaço determinados de trabalho, alcança o universo da formação de pesquisadores, delimitando, como campo de avaliação, por exemplo, os prazos para conclusão de mestrados e de doutorados. "Consegue-se assim inserir na academia um elemento que poderia ser considerado um 'segredo da acumulação primitiva': o que designamos aqui de 'surto produtivista', complementado por um 'surto competitivo' [...]”' (BIANCHETTI; MACHADO, 2009, p. 56), como reflexo de uma vinculação entre avaliação e financiamento. A forma que envolve a produção acadêmica torna essa atividade mecânica, uma vez que retira do 
pesquisador as condições favoráveis e lhe reduz o tempo necessário para a construção de trabalhos consistentes (VOSGERAU; ORLANDO; MEYER, 2017).

Bianchetti e Machado descrevem diversos estudos que tratam do sofrimento mental em cursos de formação de pesquisadores, relações entre trabalho e pós-graduação, aumento da competição na ciência brasileira e dificuldades de se sobreviver a uma tese de doutorado. A existência desses estudos configura-se como indicativos daquilo que vem sendo enfrentado no mundo acadêmico e que não se diferencia das vivências do mundo do trabalho.

Além dos sinais de sofrimento psíquico citados por Shigaki e Patrus (2006) e Bianchetti e Machado (2009) sugerem algumas consequências do produtivismo acadêmico. Entre elas é possível encontrar o trabalho docente intensificado; (de)formação na produção da nova geração de pesquisadores; publicações repetidas; prejuízos à saúde dos pesquisadores; clima de terror nas instituições de ensino superior e baixa qualidade nas publicações. Neste sentido, outro ponto ganha destaque nas palavras de Vosgerau, Orlando e Meyer (2017), que diz respeito à identidade docente. Dentro dos moldes de avaliação das universidades, deixa-se de lado a valorização da formação didático-pedagógica do professor, considerando apenas sua intensa capacidade de produção científica nos tempos estabelecidos.

\footnotetext{
Em um contexto de economia global, compreendem essa aceleração como um desdobramento da Revolução Industrial e do cronômetro taylorista, traçando um paralelo entre o espaço de produção fabril e o espaço de produção científica, ambos voltados para a maximização da produção, devidamente mensurados por indicadores que ajudam a controlar o fluxo, seja punindo os que não contribuem com os índices, seja recompensando os que adotam tempos e movimentos que alcancem a "melhor" forma de ampliar esses índices. Nesse sistema, vale o que é lido, o que é citado; e outras palavras, o que tem mercado (PATRUS; DANTAS; SHIGAKI, 2015, p. 6).
}

Essa ligação da produção acadêmica com uma racionalidade de mercado tem colocado a qualidade dos trabalhos em segundo plano. Além disso, a necessidade de se alcançar metas que possam garantir recursos para a universidade têm levado a um novo modelo de seleção de estudantes para os cursos de pós-graduação, sendo priorizado o ingresso daqueles que possuam um suposto potencial de publicação, independente da profundidade, dos benefícios ou do conhecimento produzido por suas pesquisas (PATRUS; DANTAS; SHIGAKI, 2015). Contudo, revela Silva (2009), ainda que os números apresentados e, muitas vezes comemorados, tragam otimismo no contato com um ranqueamento sobre qualidade, pouco conseguem mostrar a respeito das pressões e das estruturas que podem ser encontradas por trás de cada publicação.

Guill, Zanferrari e Almeida (2017) argumentam que as transformações de mercado trazidas para as instituições de ensino superior acabam colocando-a como ferramenta do acúmulo de capital ou, mais que isso, ingressando em uma lógica mercadológica com vistas a 
rendimentos, “[...] a universidade mecaniza e desumaniza seus participantes, concedendo a eles o status de meros 'operários pesquisadores', que estão ali apenas para cumprir seu papel de gerar um conhecimento rentável” (p. 18073). Por este prisma, a universidade abre as portas para o capital, possibilitando uma adaptação dos pesquisadores ao modelo quantitativo de produção científica que passa a ditar as regras.

Na mesma linha de pensamento de Guill, Zanferrari e Almeida, quanto à geração de conhecimento rentável, Bertolin (2018) orienta no sentido de que os olhares dos governantes em relação à universidade estão ligados aos benefícios econômicos e ao atendimento das demandas externas pelos processos de ensino e de pesquisa, o que reforça o entendimento de Silva (2009) quanto ao ethos predominante no campus.

O ethos predominante no campus caracteriza-se pelo conformismo diante das estruturas políticas e sociais e a busca incessante de mostrar produtividade. Os "improdutivos" são criticados pelos próprios colegas e excluídos de programas de mestrados e atividades afins. $E$ os envolvidos que não conseguem cumprir as metas de "produtividade" exigidas são pressionados e convidados a saírem [...] (SILVA, 2009, p. 4).

Sobre esse aspecto, Guill, Zanferrari e Almeida (2017) e Costa e Goulart (2018) advertem que a universidade, em busca de financiamentos e de seu crescimento, assume uma postura passiva frente ao capital e às suas exigências de produtividade, de prestação de serviços e de forte ligação com o mundo corporativo, como pode ser visto na criação de parques tecnológicos dentro das universidades.

As mudanças organizacionais ocorridas nas universidades compreendem, antes de tudo, uma alteração na identidade dessas instituições. Diante de promessas de desenvolvimento e de progresso, Fernandes (1975) revela que as universidades deixam de ser espaços voltados para a solução de problemas sociais, a partir da geração original de conhecimento e passam a compor estruturas de reprodução acrítica e de formação técnica para o mercado de trabalho.

\section{Uma universidade de reprodução}

Embora os teóricos da reprodução social, como Althusser (1970), Bourdieu e Passeron (1992), Durkheim (2011) e Saviani (2012), direcionam seus olhares para as relações escolares, nos trabalhos com crianças, os dados encontrados no espaço que discute o produtivismo acadêmico demonstram similaridades entre escola e universidade, uma vez que vem reproduzindo no campus o padrão de trabalho encontrado no mercado, ação que desenha estudantes para um modelo de competição e de produção acelerada. 
Bourdieu e Passeron expõem que o sistema de ensino materializado nas instituições escolares tornou-se um instrumento dócil de reprodução social em que se confrontam interesses antagônicos, mas legitimam aqueles das classes dominantes. Para tal, utilizam-se instrumentos pedagógicos para reproduzir as estruturas das classes.

Como assinalado por Bertolin (2018), as instâncias governamentais têm contribuído para uma universidade que possa dar conta das demandas apresentadas pelo mercado. Este modelo de educação aproxima-se do que é encontrado em Durkheim (2011), na introdução à sua obra pedagógica, na qual historicamente a educação está identificada conforme a sociedade em que está inserida, desenvolvendo sujeitos de acordo com as suas necessidades.

Por este prisma, o destaque feito por Saviani (2012) em relação ao papel da escola, de reproduzir a sociedade de classes e de reforçar o modo de produção capitalista, condiz com os achados de Wood Jr. (2016) que narra o produtivismo acadêmico, como uma produção científica em massa, similar ao encontrado no modelo fordista, marca indelével da sociedade capitalista.

Há, conforme visto com Bianchetti e Machado (2009), um projeto de universidade sublinhado pela produtividade e pela competição no desenvolvimento de produtos. Neste sentido, a universidade se direciona para o modelo adotado pelo meio corporativo, baseando suas atividades em avaliações quantitativas. Evidencia-se assim, a necessidade de elaboração de produtos que possam garantir recursos à instituição, não diferente do que ocorre em uma indústria. Com isso, o artigo tem se tornado o produto soberano das universidades, como revela Bernardo (2014), recebendo incentivos para sua produção em massa, com pesadas metas a serem atingidas em tempos cada vez menores, em uma clara alusão ao toyotismo.

Tendo em vista que o aumento da capacidade produtiva pode garantir um aumento dos recursos, uma vez que as avaliações da CAPES consideram esse viés para seus direcionamentos (SILVA, 2009), as seleções para os cursos de pós-graduação começam a receber novos olhares, que buscam em meio aos concorrentes, aqueles que apresentem maior potencial para publicações, como sublinham Patrus, Dantas e Shigaki (2015).

Neste ponto é possível uma aproximação com o que Althusser (1970) retrata sobre a maneira que a classe dominante se utiliza dos AIE para a garantia da manutenção da força de trabalho. Althusser leciona que devem ser concebidas conjunturas de manutenção, criando condições de reprodução não só das forças, mas das relações de produção capitalista. Neste sentido, Althusser (1970) e Fernandes (1975) são unânimes em acreditar que a universidade contribuiria a partir da qualificação e da reprodução de trabalhadores com a formação técnica, aptos e competentes a assumirem atividades nos moldes demandados pelo mercado de trabalho. 
Dessa forma a todo momento nos cabe uma reflexão quanto a nossa pesquisa e a ciência que estamos produzindo, será que estamos seguindo o caminho correto em nossas produções, ou o resultado de nosso trabalho é meramente uma expressão das demandas do capital, que acaba por contribuir para que permanecemos imóveis nesse sistema, dia após dia nos lançando no abismo da produção pela produção? (GUILL; ZANFERRARI; ALMEIDA, 2017, p. 18074).

Considerando os argumentos identificados em Althusser (1970) e Fernandes (1975), assim como a realidade exposta por Silva (2009), Bianchetti e Machado (2009) e Patrus, Dantas e Shigaki (2015), a máxima de Althusser, de que todo aparelho, ideológico ou repressivo, objetiva reproduzir a relação de produção e as relações de exploração capitalistas, torna-se cada vez mais robusta, principalmente se tomarmos como certa a orientação de Silva (2009, p. 5) de que "[...] ao poder burocrático interessa manter a ordem das coisas, sua força advém da aceitação da cultura produtivista. Seus alicerces estão bem fincados no ethos do profissional acadêmico de hoje e na aceitação acrítica das ordens de cima", criando e reproduzindo conjunturas de manutenção, como lembra Althusser (1970).

\section{Considerações finais}

O contato com autores como Althusser e Saviani revela aspectos da educação que proporcionam espaços de discussão sobre as interferências sociais na sua construção e na sua atuação. Althusser (1970) apresenta o sistema escolar enquanto Aparelho Ideológico, montado para a reprodução das relações de produção capitalista, conceito referenciado por Saviani (2012) no desenvolvimento das teorias da educação que, entre elas, ganham destaque as teorias crítico-reprodutivistas.

Estas teorias consideram a educação como um instrumento da classe dominante capaz de reproduzir o sistema "dominante-dominado", sendo responsável pela marginalização. Percebe-se a dependência da educação em relação à sociedade, tendo em sua estruturação a reprodução da sociedade na qual ela se insere (SAVIANI, 2012).

Considerando os escritos de Althusser (1970), Bourdieu e Passeron (1992), Durkheim (2011), Saviani (2012) e as investigações que revelam uma realidade de produtivismo acadêmico, o entendimento em relação aos pressupostos dos teóricos estudados pode ser ampliado da educação escolar para os campi universitários, apontando a academia como um espaço de reprodução das relações de produção capitalista. Aproximando das ideias de Bourdieu e Passeron, pode-se afirmar que o processo educativo presente nas instituições de ensino superior baseia-se em ações que revelam a manifestação da violência simbólica. 
Tomando o espaço marcado pelo produtivismo acadêmico, isso quer dizer que esta lógica implementada na educação superior seria o meio pelo qual as instituições de ensino subjugam o sujeito e a sua individualidade, obrigando-o a se posicionar no mundo social, em conformidade com as noções preestabelecidas pelo pensamento ou pela cultura dominante.

Destarte, entendendo a universidade como parte das instituições que compõem os AIE e que, desta forma, lhe compete a reprodução de uma cultura dominante, cabe frisar que não é intenção deste artigo demarcar como certas ou erradas as aproximações da universidade com os projetos corporativistas, mas sim compreendê-las a partir de um olhar crítico e apontar a inexistência de uma neutralidade ou distanciamento das demandas da sociedade.

Essas considerações aqui situadas são dinâmicas e portanto, necessitam ser atualizadas e adensadas em outros trabalhos de pesquisa. Trata-se de um tema fecundo para novas investigações, não só para recriar os conceitos e os fundamentos das teorias críticoreprodutivistas, como para contribuir no processo de desenvolvimento da educação superior, recriando este espaço que parece caracterizado como reprodução das formações sociais dominantes.

\section{Referências}

ALTHUSSER, Louis. Ideologia e aparelhos ideológicos do Estado. Lisboa: Editorial Presença, 1970.

BERNARDO, Marcia Hespanhol. Produtivismo e precariedade subjetiva na universidade pública: o desgaste mental dos docentes. Psicologia \& Sociedade, Belo Horizonte, v. 26, n. extra 3, p. 129-139, 2014.

BERTOLIN, Julio Cesar Godoy. Ideologias e percepções da educação superior: da dicotomia entre o social e o econômico ao 'caminho do meio'. Horizontes, São Paulo, v. 36, n. 3, p. 86101, set./dez. 2018.

BIANCHETTI, Lucídio; VALLE, Ione Ribeiro. Produtivismo acadêmico e decorrências às condições de vida/trabalho de pesquisadores brasileiros e europeus. Ensaio: aval. pol. públ. Educ., Rio de Janeiro, v. 22, n. 82, p. 89-110, jan./mar. 2014. Disponível em: https://www.scielo.br/pdf/ensaio/v22n82/a05v22n82.pdf . Acesso em: 8 mar. 2020.

BIANCHETTI, Lucídio; MACHADO, Ana Maria Netto. Publicar e Morrer!? Análise do impacto das políticas de pesquisa e pós-graduação na constituição do tempo de trabalho dos investigadores. Educação, Sociedades e Culturas, Porto/PT, n. 28, p. 53-69, 2009.

BOURDIEU, Pierre; PASSERON, Jean Claude. A reprodução: elementos para uma teoria do sistema de ensino. 3. ed. Rio de Janeiro: Livraria Francisco Alves, 1992. 
CASTANHA, Renata Cristina Gutierres; GRÁCIO, Maria Cláudia Cabrini. Contribuição da análise multivariada para os indicadores de avaliação dos programas de pós-graduação: uma análise na área de Matemática (2007-2009). Em Questão, Porto Alegre, v. 21, n. 2, jan./abr. 2015.

COSTA, Camila Furlan da; GOULART, Sueli. Capitalismo acadêmico e reformas neoliberais no ensino superior brasileiro. Cad. EBAPE.BR, Rio de Janeiro, v. 16, n. 13, p. 396-409, jul./set. 2018.

DIAS, Rafael; SERAFIM, Milena. Comentários sobre as transformações recentes na universidade pública brasileira. Avaliação, Campinas; Sorocaba, SP, v. 20, n. 2, p. 335-351, jul. 2015. Disponível em: https://www.scielo.br/pdf/aval/v20n2/1414-4077-aval-20-0200335.pdf. Acesso em: 16 mar. 2020.

DURKHEIM, Émile. Educação e sociologia. Petrópolis: Vozes, 2011.

GONÇALVES, Andréa; RAMOS, Lúcia Maria S. V. Costa; CASTRO, Regina C. Figueiredo. Revistas científicas: características, funções e critérios de qualidade. In: POBLACION, Dinah Aguiar; WITTER, Geraldina Porto; SILVA, José Fernando Modesto da (orgs.).

Comunicação \& produção científica: contexto, indicadores e avaliação. São Paulo: Angellara, 2006. p. 163-190.

FERNANDES, Florestan. Universidade brasileira: reforma ou revolução? São Paulo: AlfaOmega, 1975.

GUILL, Thalles Fellipe; ZANFERRARI, Talita; ALMEIDA, Maria de Lourdes Pinto de. Produtivismo acadêmico, suas origens e consequências. In: EDUCERE. CONGRESSO NACIONAL DE EDUCAÇÃO, 13., 2017, Curitiba. Anais eletrônicos [...]. Curitiba: Pontifícia Universidade Católica do Paraná, 2017, p. 18071-18086. Disponível em: https://educere.bruc.com.br/arquivo/pdf2017/26343_13943.pdf. Acesso em: 8 mar. 2020.

KUNZ, Elenor. Pós-graduação em Educação Física no Brasil: o fenômeno da hiperprodutividade e formação cultural. Revista Kinesis, Santa Maria, v. 30, n. 1, p. 1-13, jul. 2012.

MINAYO, Maria Cecília de Souza. O desafio do conhecimento: pesquisa qualitativa em saúde. 8. ed. São Paulo: Hucitec, 2004.

OLIVEIRA, Marcos Barbosa. Desmercantilizar a tecnociência. In: SANTOS, Boaventura de Souza (org.). Conhecimento prudente para uma vida decente: um discurso sobre as ciências revisitado. São Paulo: Cortez, 2006.

PATRUS, Roberto; DANTAS, Douglas Cabral; SHIGAKI, Helena Belintani. O produtivismo acadêmico e seus impactos na pós-graduação stricto sensu: uma ameaça à solidariedade entre pares. Cad. EBAPE.BR, Rio de Janeiro, v. 13, n. 1, p. 1-18, jan./mar. 2015.

SAVIANI, Demerval. Escola e democracia. 42. ed. Campinas: Autores Associados, 2012.

SGUISSARDI, Valdemar. Produtivismo acadêmico. In: OLIVEIRA, Dalila Andrade; DUARTE, Adriana Maria Cancella; VIEIRA, Livia Maria Fraga (org.). Dicionário de 
trabalho, profissão e condição docente. Belo Horizonte: Faculdade de Educação UFMG, 2010.

SGUISSARDI, Valdemar; SILVA JÚNIOR, João dos Reis. Trabalho intensificado nas federais: pós-graduação e produtivismo acadêmico. São Paulo: Xamã, 2009.

SHIGAKI, Helena Belintani; PATRUS, Roberto. Revisão por pares e produtivismo acadêmico sob a ótica de avaliadores de artigos de periódicos em Administração. Revista Brasileira de Pós-Graduação, Brasília, v. 13, n. 21, p. 399-428, maio/ago. 2016.

SILVA, Antonio Ozaí da. Produtivismo no campo acadêmico: o engodo dos números. Revista Espaço Acadêmico, Maringá, n. 100, p. 1-5, set. 2009.

SILVA JUNIOR, Vagner Pereira da; GONÇALVES-SILVA, Luiza Lana; MOREIRA, Wagner Wey. Produtivismo na pós-graduação. Nada é tão ruim, que não possa piorar. É chegada a vez dos orientandos! Movimento, Porto Alegre, v. 20, n. 4, p. 1423-1445, out./dez. 2014.

SLAUGHTER, Sheila; LESLIE, Larry L. Academic capitalism: politics, policies and the entrepreneurial university. Baltimore: Johns Hopkins, 1997.

VOSGERAU, Dilmeire Sant'Anna Ramos; ORLANDO, Evelyn Almeida; MEYER, Patricia. Produtivismo acadêmico e suas repercussões no desenvolvimento profissional de professores universitários. Educ. Soc., Campinas, v. 38, n. 138, p. 231-247, jan. 2017.

WOOD JR., Thomaz. Origens do produtivismo acadêmico e o caminho do impacto social do conhecimento. Ensino Superior, Campinas, maio 2016. Disponível em:

https://www.revistaensinosuperior.gr.unicamp.br/artigos/origens-do-produtivismo-academicoe-o-caminho-do-impacto-social-do-conhecimento. Acesso em: 16 mar. 2020. 